\title{
The impact of challenge gifts on charitable giving: an experimental investigation
}

\author{
John A. List ${ }^{\mathrm{a}}$, Daniel Rondeau ${ }^{\mathrm{b}, *}$ \\ a Agricultural Resource Economics Department, University of Maryland, College Park, MD, USA \\ ${ }^{\mathrm{b}}$ Department of Economics, University of Victoria, P.O. Box 1700 STN CSC, Victoria, British Columbia, \\ Canada V8W $2 Y 2$
}

Received 6 May 2002; received in revised form 30 July 2002; accepted 4 September 2002

\begin{abstract}
Evidence suggests that contributions to capital campaigns increase with the value of leadership gifts. We examine the response of subjects to the announcement of leadership gifts and its implied change in the campaign's target. The two effects are partitioned.
\end{abstract}

(C) 2002 Elsevier Science B.V. All rights reserved.

Keywords: Charitable giving; Threshold public goods; Experiments

JEL classification: C91 (Laboratory Experiments); H41 (Public Goods)

\section{Introduction}

The optimal behavior of fundraisers remains one of the most under-researched areas within economics. This is curious given that some estimates suggest that fundraisers spend $\$ 2$ billion per year on a variety of strategies aimed at successfully reaching specified funding targets (Kelley, 1997). Among them, the quiet solicitation of leadership donations as a stepping-stone to a broader public campaign is increasingly touted as an essential ingredient of success. Professional fund raising consultants advise securing leadership gifts worth a minimum of $10 \%$, but preferably as much as $80 \%$ of the overall objective of a capital campaign before launching an appeal for contributions from the general public (Dove, 2000).

Leadership Gifts can be used in several ways by fundraisers. As a Challenge Gift, the Leadership contribution is a commitment (often legally binding) by a particular donor to provide a given sum of

\footnotetext{
*Corresponding author. Tel.: + 1-205-472-4423; fax: + 1-250-721-6214.

E-mail addresses: jlist@arec.umd.edu (J.A. List), rondeau@uvic.ca (D. Rondeau).
} 
money, contingent on the fund raising objective being met (inclusive of the leadership gift). Andreoni (1998) models such contingent commitments and shows that Challenge Gifts can overcome free riding equilibria in an environment populated by altruistic individuals.

List and Lucking-Reiley (2002) use direct mail solicitation of 3000 Central Florida residents to confirm that total contributions increase with the amount of Challenge Contributions announced by the fund raiser. In their field experiment, increasing the amount of announced Challenge Contributions from 10 to $67 \%$ of the campaign goal resulted in nearly a 6 -fold increase in contributions by the general public. While the results in List and Lucking-Reiley (2002) are in line with the wisdom of fund-raisers, it is worth noting that increasing the amount of leadership contributions potentially has two opposite effects on public contributions. On the one hand, the amount of seed money potentially sends a positive signal to potential donors regarding the quality of the charity (Vesterlund, 2002). ${ }^{2}$

On the other hand, increasing the amount of leadership contributions in threshold public good environments like those of List and Lucking-Reiley and most other capital campaigns, decreases the aggregate amount of money actually required in donations from the general public in order to fund the project. The isolated effect of changing the threshold on contributions is not entirely understood, but the weight of available evidence suggests that decreasing the threshold discourages contributions. We provide new evidence of this effect below.

An important question is therefore left unanswered: to what extent are subjects responding to the informational content of leadership contributions and to the effective lowering of the provision point? This note explores this question in the context of an induced value provision point public good experiment. In the next section, we present the experimental design. Section 3 contains the results and is followed by final remarks.

\section{Experimental design}

Subjects for our experiment were recruited from the undergraduate student body at the University of Central Florida in Orlando. Subjects signed a consent form in which they acknowledge their voluntary participation in the experiment and agree to abide by the rules of the experiment.

In an experimental protocol that parallels the work of Rondeau et al. (1999), participants in groups of 10 were initially endowed with $\$ 15$ and asked to divide this amount between a private account and a group investment fund in a one-shot decision environment. Any split was allowed provided each amount was non-negative and the sum allocated to the two accounts equaled $\$ 15$.

In each treatment, a threshold level of contributions to the group fund was required to provide the public good. Failure to reach the threshold resulted in a refund of all contributions to the group fund. Contributions in excess of the threshold were transformed into additional benefits at the rate of $\$ 0.05$ and \$0.08 per dollar in excess contributions in the low and high-induced value treatments,

\footnotetext{
${ }^{1}$ More specifically, Andreoni's (1998) model has multiple equilibria, and in the absence of seed money there exists a Nash equilibrium with zero charitable giving.

${ }^{2}$ Potters et al. (2001) demonstrate how Leadership Gifts may be used as a signaling device in a two-player voluntary contributions experiment without a threshold.
} 
Table 1

Experimental design

\begin{tabular}{llll}
\hline $\begin{array}{l}\text { Induced } \\
\text { value }\end{array}$ & $\mathrm{PP}=\$ 44$ & $\mathrm{PP}=\$ 44$ & $\mathrm{PP}=\$ 26$ \\
\hline$\$ 5$ & $\mathrm{LCC}=0$ & $\mathrm{PCC}=\$ 18$ & $\mathrm{PCC}=0$ \\
$\$ 8$ & $\mathrm{H} \$ 44 \$ 0$ & $\mathrm{~L} \$ 44 \$ 18$ & $\mathrm{~L} \$ 26 \$ 0$ \\
\hline
\end{tabular}

L $\$ 44 \$ 0$ in row 1 , column 1 denotes low induced value (\$5), a provision point of $\$ 44$, and $\$ 0$ in Challenge Contributions.

respectively. Thus, with all treatments conducted with groups of 10 , excess contributions resulted in a net loss to the group.

Our simple $2 \times 3$ experimental design consists of the six treatments outlined in Table 1 . For each of a Low and High induced value amount (\$5 in Row 1 and $\$ 8$ in Row 2, respectively), a control treatment ( $\mathrm{L} \$ 4 \$ 0$ and $\mathrm{H} \$ 44 \$ 0)$ was conducted with a provision point of $\$ 44$ and $\$ 0$ in Challenge Contributions. The first departure from these controls are treatments $\mathrm{L} \$ 44 \$ 18$ and $\mathrm{H} \$ 44 \$ 18$, which serve to provide a robustness test of List and Lucking-Reiley (2002). In these treatments, Challenge Contributions of $\$ 18$ were announced while maintaining the original provision point of $\$ 44$. Therefore, accounting for seed money, the amount of contributions actually required from the group is $\$ 26$. To complete the experimental design, we conducted two additional treatments: L\$26\$0 and $\mathrm{H} \$ 26 \$ 0$. In these treatments, we announced a provision point of $\$ 26$ but no Challenge Contributions. Thus, when comparing data from these treatments with the baseline, we can obtain insights into the consequences on charitable contributions of changing the provision point.

Before proceeding to our discussion of the experimental results, a few points deserve brief mention. First, the data were collected through six 30-min sessions, each session corresponding to one of our treatments. A total of 180 subjects earned an average of $\$ 16.50$ each. Second, in all treatments, payoff information was private-subjects were informed that "the payoffs of other members of your group may differ from yours". All other aspects of the game were common knowledge. In the two treatments with Challenge Gifts, subjects were informed that 'an outside investor' had already committed an amount of $\$ 18$ to the group investment fund and that the sum of investments by the group and the outside investor had to exceed the threshold of $\$ 44$ in order for the group investment fund to return a payoff to group members.

Third, we should note that there is no uncertainty about the quality of the public good. Thus, unlike List and Lucking-Reiley (2002), there is no (potentially) hidden quality to the good. However, the informational setting in the laboratory does not necessarily mean that subjects fail to take the Challenge Gift of the generic 'outside investor' as a signal of quality. We submit that it is safe to assume, however, that any signaling value of the 'outside investor' will be weak in a laboratory setting. This set-up is also consistent with the form of the field experiments of List and LuckingReiley (2002). ${ }^{3}$ The certainty about the quality of the laboratory good further downplays the signaling role of challenge gifts. Thus, failure to observe a challenge gift effect in the laboratory would lend

\footnotetext{
${ }^{3}$ List and Lucking-Riley announce the challenge gift in the following manner: "We have already obtained funds to cover $10 \%$ of the cost for this computer, so we are soliciting donations to cover the remaining $\$ 2700$ ”.
} 
support to a 'generic' hypothesis that signaling positively affects contributions in the field. However, it is also plausible that challenge gifts in both the field and lab put social pressure on subjects and induce donations.

\section{Experimental results}

Descriptive statistics for the treatments are reported in Table 2. At a glance, this set of treatments produced an amazingly small amount of variation: mean contributions varied from $\$ 6.76$ in the low value, low provision point no challenge gift treatment (L\$26\$0) to $\$ 9.25$ in the high value, high provision point with challenge gift treatment $(\mathrm{H} \$ 44 \$ 18)$. The median contribution is exactly $\$ 9.00$ in four of the treatments and only the L $\$ 26 \$ 0$ appears to be somewhat smaller than the others at $\$ 5.00$.

Jarque-Berra test statistics indicate that the null hypothesis that the data is normally distributed cannot be rejected at conventional significance levels for any of the six data distributions. This finding provides confidence in the power of the parametric tests we employ below.

A summary of the statistical tests of the equality of average contributions across pairs of treatments is presented in Table 3. We also report the results of Mann-Whitney tests of the equality of medians in Table 4.

Comparing $\mathrm{L} \$ 44 \$ 0(\mathrm{H} \$ 44 \$ 0)$ and $\mathrm{L} \$ 44 \$ 18(\mathrm{H} \$ 44 \$ 18)$ provides a measure of the (total) net effect on contributions of introducing a Challenge Gift. For the low value treatments (and similarly for the high value treatments) comparisons of both the means and medians fail to reject the null hypotheses that contributions are equal at standard confidence levels. Probabilities that the means are equal are, respectively, 0.958 and 0.577 for the low and high value pairs. Analyses of medians yield similar insights, with probabilities of equality standing at 0.876 and 0.676 in the low and high value treatments, respectively.

Thus, we do not observe, in the laboratory, an increase in contributions similar to that of List and

Table 2

Summary statistics

\begin{tabular}{lcccccc}
\hline & $\mathrm{L} \$ 26 \$ 0$ & $\mathrm{~L} \$ 44 \$ 0$ & $\mathrm{~L} \$ 44 \$ 18$ & $\mathrm{H} \$ 26 \$ 0$ & $\mathrm{H} \$ 44 \$ 0$ & $\mathrm{H} \$ 44 \$ 18$ \\
\hline Mean (\$) & 6.757 & 8.333 & 8.390 & 9.117 & 8.647 & 9.253 \\
Median (\$) & 5.00 & 9.00 & 9.00 & 9.00 & 9.00 & 9.50 \\
Maximum (\$) & 15.00 & 15.00 & 15.00 & 15.00 & 15.00 & 15.00 \\
Minimum (\$) & 1.00 & 0.00 & 1.00 & 0.00 & 0.00 & 2.60 \\
S.D. (\$) & 5.059 & 4.423 & 3.933 & 4.756 & 4.599 & 3.735 \\
Jarque-Bera & 4.072 & 0.610 & 0.860 & 1.454 & 1.418 & 1.034 \\
Probability & 0.131 & 0.737 & 0.650 & 0.483 & 0.492 & 0.596 \\
Sum (\$) & 202.71 & 250.00 & 251.700 & 273.50 & 259.40 & 277.60 \\
Observations & 30 & 30 & 30 & 30 & 30 & 30 \\
\hline
\end{tabular}

\footnotetext{
${ }^{4}$ The hypothesis of an informational effect is generic in the sense that we impose no structure and make no assumption about the type of uncertainty surrounding the quality of the good, what information is conveyed by Challenge Gifts, how beliefs are formed, or about the value of such information.
} 
Table 3

Two-sided $t$-tests of the equality of means $t$-statistics (probability of equality)

\begin{tabular}{|c|c|c|c|c|c|c|}
\hline & $\mathrm{L} \$ 26 \$ 0$ & $\mathrm{~L} \$ 44 \$ 0$ & $\mathrm{~L} \$ 44 \$ 18$ & $\mathrm{H} \$ 26 \$ 0$ & $\mathrm{H} \$ 44 \$ 0$ & $\mathrm{H} \$ 44 \$ 18$ \\
\hline $\mathrm{L} \$ 26 \$ 0$ & $* * *$ & $\begin{array}{c}1.285 \\
(0.204)\end{array}$ & $\begin{array}{c}1.396 \\
(0.168)\end{array}$ & $\begin{array}{c}1.861 \\
(0.068)\end{array}$ & & \\
\hline $\mathrm{L} \$ 44 \$ 0$ & & $* * *$ & $\begin{array}{c}0.052 \\
(0.958)\end{array}$ & & $\begin{array}{c}0.269 \\
(0.789)\end{array}$ & \\
\hline $\mathrm{L} \$ 44 \$ 18$ & & & $* * *$ & & & $\begin{array}{c}0.872 \\
(0.387)\end{array}$ \\
\hline $\mathrm{H} \$ 26 \$ 0$ & & & & $* * *$ & $\begin{array}{c}0.389 \\
(0.699)\end{array}$ & $\begin{array}{c}0.124 \\
(0.902)\end{array}$ \\
\hline $\mathrm{H} \$ 44 \$ 0$ & & & & & $* * *$ & $\begin{array}{c}0.561 \\
(0.577)\end{array}$ \\
\hline $\mathrm{H} \$ 44 \$ 18$ & & & & & & $* * *$ \\
\hline
\end{tabular}

Lucking-Reiley (2002). Despite this result, the decomposition of the total effect into its provision point and Challenge Gift components provides some insights into the relative importance of each effect.

The Provision Point effect is measured independently via a comparison of contributions in the $\mathrm{L} \$ 44 \$ 0(\mathrm{H} \$ 44 \$ 0)$ and $\mathrm{L} \$ 26 \$ 0(\mathrm{H} \$ 26 \$ 0)$. In both treatments, no Challenge contributions were announced; hence the change in the threshold from \$26 to \$44 is the only variable affecting the results. In Tables 3 and 4, the null hypothesis that contributions are equal in both treatments is tested against inequality (two-tailed tests). While no statistical differences can be detected in the high value treatments, we find in the low value treatments that median contributions are significantly greater (at the $10 \%$ confidence level) when the threshold is set at $\$ 44$ than when only $\$ 26$ are required $(P=0.0815)$.

This result is somewhat muted when one considers average contributions. Although larger in the $\$ 44$ threshold treatment ( $\$ 8.33$ versus $\$ 6.76$ ), the probability of a difference between the two averages is $P=0.204$. If one considers the results in Ledyard (1995), and our new analysis of early round data

Table 4

Two-sided Mann-Whitney tests of the equality of medians $z$-statistics (probability of equality)

\begin{tabular}{|c|c|c|c|c|c|c|}
\hline & $\mathrm{L} \$ 26 \$ 0$ & $\mathrm{~L} \$ 44 \$ 0$ & $\mathrm{~L} \$ 44 \$ 18$ & $\mathrm{H} \$ 26 \$ 0$ & $\mathrm{H} \$ 44 \$ 0$ & $\mathrm{H} \$ 44 \$ 18$ \\
\hline $\mathrm{L} \$ 26 \$ 0$ & $* * *$ & $\begin{array}{c}1.742 \\
(0.082)\end{array}$ & $\begin{array}{c}1.597 \\
(0.110)\end{array}$ & $\begin{array}{c}1.940 \\
(0.052)\end{array}$ & & \\
\hline $\mathrm{L} \$ 44 \$ 0$ & & $* * *$ & $\begin{array}{c}0.156 \\
(0.876)\end{array}$ & & $\begin{array}{c}0.179 \\
(0.859)\end{array}$ & \\
\hline $\mathrm{L} \$ 44 \$ 18$ & & & $* * *$ & & & $\begin{array}{c}0.717 \\
(0.473)\end{array}$ \\
\hline $\mathrm{H} \$ 26 \$ 0$ & & & & $* * *$ & $\begin{array}{c}0.447 \\
(0.655)\end{array}$ & $\begin{array}{c}0.119 \\
(0.905)\end{array}$ \\
\hline $\mathrm{H} \$ 44 \$ 0$ & & & & & $* * *$ & $\begin{array}{c}0.418 \\
(0.676)\end{array}$ \\
\hline $\mathrm{H} \$ 44 \$ 18$ & & & & & & $* * *$ \\
\hline
\end{tabular}


from Cadsby and Maynes (1999), a one-tailed test may be more appropriate. In this case, of course, contributions in the $\mathrm{L} \$ 44 \$ 0$ treatment are greater than those in the $\mathrm{L} \$ 26 \$ 0$ treatment at the $P=0.102$ level.

The information content of the 'outside investor' and his Challenge Gift is isolated in a comparison of $\mathrm{L} \$ 44 \$ 18(\mathrm{H} \$ 44 \$ 18)$ and $\mathrm{L} \$ 26 \$ 0(\mathrm{H} \$ 26 \$ 0)$. In these treatments, the effective amount of contributions required is maintained constant at $\$ 26$ - the only change is a framing of the treatment in which an increase of $\$ 18$ in the threshold matched by an equal Challenge Gift provided by the outside investor. Once again, the high value treatments show no significant effect, while the low value treatments provide some positive evidence of a challenge gift effect. The two-tailed test of equality of the means produces a $P$ value of 0.168 , which translates into a one-sided probability of 0.084 . The two-sided median Mann-Whitney test produces a $P$ value of 0.11 , again marginally close to the $10 \%$ confidence level.

\section{Concluding remarks}

We designed an experiment to examine the response of subjects to the announcement of leadership contributions and changes in the provision point. We find that for certain treatments, announcing leadership contributions has value, even in laboratory settings where the 'Outside Investor' is no more than a framing device. Even with such a weak device, it is remarkable that the positive effects of Challenge Gifts on contributions (either through signaling or contribution-increasing social pressure) was sufficient to eliminate the negative effect created by the implicit reduction in the threshold required to fund the public good. Though these laboratory results are clearly not as strong as the field results of List and Lucking-Reiley (2002), the treatments conducted herein demonstrate that Challenge Gifts have two opposite effects on charitable giving toward the funding of threshold public goods.

Differences between field and laboratory settings may also help explain the differing strengths of these effects. Aside from the usual subject and house money arguments, we suspect that strategic considerations may make the threshold effect much stronger in the laboratory than in the field. The provision point mechanism is a difficult coordination game in which subjects collectively wish to fund the good at minimum individual cost. In the lab, a large effective threshold increases the average individual contribution necessary to fund the public good. This average seems more likely to be used as an approximate basis for coordination (a weak focal point) by laboratory subjects than by the general citizenry. Gamesmanship over this aspect of a fund raising campaign seems more likely in the laboratory than in the field. Conversely, the informational content of seed money seems more potent

\footnotetext{
${ }^{5}$ We re-analyzed the data from Cadsby and Maynes (1999) for the first round of treatments with continuous contributions and money back guarantee (110 observations). In Tobit regressions of individual contributions on a constant, induced value, and threshold, we find the level of the provision point to be a strong predictor of individual contributions. The coefficient takes a value of 0.0894 with a probability $P<0.0001$ that the coefficient on the provision point is equal to zero. Thus, in the groups of 10 implemented by Cadsby and Maynes, increasing the threshold by $\$ 1.00$ results in an average increase in total group contributions of \$0.894. This is consistent with Cadsby and Maynes' (1999) published results in which they find that for the last five rounds of their experiments, the parameter on the provision point is not statistically different from zero in a regression where the dependent variable is the mean group contribution as a fraction of the threshold. Therefore, as the threshold increases, Cadsby and Maynes (1999) cannot reject that a proportional increase in absolute contributions takes place, just as we report here.
} 
in the field than in the lab, unless, as in Potters et al. (2001), the experimental design imposes uncertainty about the quality of the good and induces a value of information.

\section{Acknowledgements}

We thank the University of Central Florida's STAR program and a summer research grant for financially supporting this work. Thanks are also extended to the University of Victoria for its financial support through an internal grant funded by the Social Sciences and Humanities Research Council of Canada. We finally acknowledge the able research assistance provided by Apinya Thumaphipol and Priti Manek, and the valuable comments of an anonymous referee.

\section{References}

Andreoni, J., 1998. Toward a theory of charitable fund-raising. Journal of Political Economy 106, $1186-1213$.

Cadsby, C.B., Maynes, E., 1999. Voluntary provision of threshold public goods with continuous contributions: experimental evidence. Journal of Public Economics 71, 53-73.

Dove, K.E., 2000. In: Conducting a Successful Capital Campaign, 2nd Edition. Jossey-Bass, San Francisco, CA.

Kelley, K.S., 1997. From motivation to mutual understanding: shifting the domain of donor research. In: Burlingame, D. (Ed.), Critical Issues in Fundraising. Wiley, New York.

Ledyard, J.O., 1995. Public goods: a survey of experimental research. In: Kagel, J.H., Roth, A.E. (Eds.), Handbook of Experimental Economics. Princeton University Press, Princeton, NJ, pp. 111-194.

List, J.A., Lucking-Reiley, D., 2002. The effects of seed money and refunds on charitable giving: experimental evidence from a University capital campaign. Journal of Political Economy 110, 215-233.

Potters, J., Sefton, M., Vesterlund, L., 2001. Why announce leadership contributions? An experimental study of the signaling and reciprocity hypotheses, CentER Discussion Paper 2001-100, Tilburg University, Holland.

Rondeau, D., Schulze, D.W., Poe, G.L., 1999. Voluntary revelation of the demand for public goods using a provision point mechanism. Journal of Public Economics 72, 455-470.

Vesterlund. L., 2002. The informational value of sequential fundraising. Journal of Public Economics (forthcoming). 